\title{
EFICIÊNCIA DE INCORPORAÇÃO DE CETOPROFENO EM PARTÍCULAS DESENVOLVIDAS A PARTIR DA BLENDA DE SERICINA E ALGINATO
}

\author{
R. D. J. SANTOS ${ }^{1}$, E. D. FREITAS ${ }^{1}$, P. C. P. ROSA ${ }^{2}$, M. G. C. $\operatorname{SILVA}^{1}$ e M. G. A. VIEIRA ${ }^{1}$ \\ ${ }^{1}$ Universidade Estadual de Campinas, Faculdade de Engenharia Química \\ ${ }^{2}$ Universidade Estadual de Campinas, Faculdade de Ciências Farmacêuticas \\ E-mail para contato: melissagav@ feq.unicamp.br
}

\begin{abstract}
RESUMO - A finalidade deste estudo foi avaliar a eficiência da incorporação de cetoprofeno em blenda de sericina com alginato. A partir de técnicas de extração de sericina por via física através de autoclave e gotejamento em solução de $\mathrm{CaCl}_{2}$ $3 \%$, foi possível formar as partículas de blenda sericina-alginato e cetoprofeno. A partir das partículas, foram realizados ensaios de incorporação, para determinar a eficiência de incorporação do cetoprofeno à blenda. Observou-se que a sericina contribui para melhorar a eficiência de incorporação e a geometria das partículas, quando comparada às partículas somente com alginato. Além disso, a adição do reticulante polietilenoglicol se mostrou dispensável. As melhores partículas produzidas foram aquelas com o maior equilíbrio nas quantidades de sericina e alginato, apresentando partículas homogêneas e eficiência de incorporação acima de $70 \%$.
\end{abstract}

\section{INTRODUÇÃO}

Para a produção da seda utiliza-se a fibroína, proteína insolúvel encontrada nos casulos do Bombyx mori, popularmente conhecido como bicho-da-seda. Outra proteína presente no casulo, a sericina costuma ser descartada como resíduo pela indústria têxtil, sendo responsável por problemas ambientais em virtude da elevada demanda de oxigênio em seu processo de degradação. Devido às suas propriedades, como biocompatibilidade e biodegradabilidade, ela pode apresentar um significativo valor econômico para a indústria farmacêutica (Aramwit et al., 2012).

A sericina apresenta-se em solução como um hidrogel à temperatura ambiente, de modo que, devido à sua estrutura e presença de grupos laterais polares, torna-se solúvel em água a elevadas temperaturas e permite a reticulação, polimerização ou formação de blendas com outros polímeros, como por exemplo, o alginato de sódio. A combinação da sericina com o alginato pode ser aplicada na indústria farmacêutica como uma blenda com característica gastrorresistente, evitando que as propriedades dos fármacos incorporados sejam afetadas e, por consequência, permita o controle de sua liberação (Aramwit et al.,2012, Vidart et al., 2015).

O estudo de novas formas de liberação de fármacos a partir de princípios ativos já existentes apresenta a vantagem de diminuir os efeitos colaterais, além de permitir melhor 
absorção do ativo. O cetoprofeno é uma substância com propriedades anti-inflamatória, analgésica, antitérmica e antitrombótica (Castagnetti e Mariella, 2015). Por apresentar tempo de meia-vida curto, cerca de 2 a 3 horas, e quando exposto ao meio gástrico poder causar irritações na muscosa, torna-se um bom candidato ao sistema de liberação controlada. Com isso, pode-se dispensar a necessidade de frequentes administrações para manter seus níveis terapêuticos e reduzir seus efeitos irritantes à mucosa intestinal (Moreira et al, 2012).

Com isso, o presente estudo buscou desenvolver partículas a partir da blenda de sericina e alginato, visando utilizá-las para incorporação de cetoprofeno como uma forma de liberação controlada de fármacos. A sericina foi extraída dos casulos do Bombyx mori e o alginato foi obtido comercialmente. A fim de determinar a eficiência de incorporação, foram realizados ensaios de incorporação.

\section{METODOLOGIA}

\subsection{Material}

Foram utilizados casulos do bicho-da-seda Bombyx mori obtidos na empresa de fiação de seda BRATAC, com sede na cidade de Londrina-PR. O cetoprofeno utilizado foi fornecido pela empresa Purifarma enquanto o alginato de sódio utilizado para a formação da blenda com a sericina e o agente reticulante polietilenoglicol (PEG) foram fornecidos pela Sigma-Aldrich.

\subsection{Extração e fracionamento da sericina}

Inicialmente, os casulos do bicho-da-seda foram limpos e cortados com o auxílio de tesouras e pinças e, posteriormente, foram lavados em água corrente e água deionizada. Para secar, os casulos foram dispostos em bandejas em estufa a $50{ }^{\circ} \mathrm{C}$.

Para a extração de sericina, utilizou-se o método por autoclave na pressão manométrica de $1 \mathrm{kgf} / \mathrm{cm}^{2}$, temperatura de $120^{\circ} \mathrm{C}$, durante 40 minutos, tendo como base o estudo de Tomadon Jr (2011). Na proporção de 40:1 (gramas de casulo:litro de água), os casulos à temperatura ambiente foram transferidos para um Erlenmeyer com água destilada e procedeu-se à extração. A solução extraída foi transferida e mantida em um recipiente fechado à temperatura ambiente por cerca de 12 horas, adquirindo o aspecto de um hidrogel, e posteriormente, foi acondicionada em congelador por, pelo menos, 24 horas.

Após este período, foi realizado o fracionamento da sericina pela técnica de congelamento/descongelamento. A solução foi descongelada à temperatura ambiente e, com um papel de filtro qualitativo, realizou-se a separação de fases da solução aquosa do sobrenadante que continha proteínas insolubilizadas. Para a produção de partículas, foi necessário ajustar a concentração da solução de sericina para $2,5 \%(\mathrm{~m} / \mathrm{V})$ utilizando o método das massas (Silva et al., 2013).

\subsection{Preparação das partículas e incorporação dos fármacos}

Como proposto por Khandai et al. (2010), para a incorporação do cetoprofeno, a solução de sericina $2,5 \%(\mathrm{~m} / \mathrm{V})$ foi aquecida a $70^{\circ} \mathrm{C}$ durante 10 minutos, e então foi agitada mecanicamente a $4000 \mathrm{rpm}$ em Ultraturrax ${ }^{\circledR}$. Após a solução ter atingido $55^{\circ} \mathrm{C}$, o alginato de 
sódio foi adicionado em diferentes proporções, e mantido sob agitação até a completa homogeneização. Posteriormente, foram adicionados à blenda 2,0 $\mathrm{g}$ de cetoprofeno a cada uma das diferentes formulações (C1, C2, C3, C4, C5) e a solução voltou a ser agitada, a 4000 rpm e, depois, a $8000 \mathrm{rpm}$, até que o fármaco fosse completamente dissolvido. As diferentes formulações preparadas são apresentadas na Tabela 1. Tais formulações foram escolhidas com base nos resultados de Soares et al. (2015) e Vidart et al. (2015), que avaliaram a eficiência de incorporação de diclofenaco de sódio na blenda de sericina e alginato, obtendo melhores resultados em blendas com $2 \%(\mathrm{~m} / \mathrm{V})$ de fármaco e na faixa de $1-2,8 \%(\mathrm{~m} / \mathrm{V})$ de alginato de sódio. Na partícula C4 foi incorporado PEG com o objetivo de avaliar a influência de um agente reticulante na produção de partículas e incorporação de fármaco. Experimentalmente, esse reagente é adicionado após a incorporação do fármaco, sob agitação constante.

Tabela 1 - Formulações das partículas de sericina, alginato de sódio, cetoprofeno e PEG incorporado.

\begin{tabular}{|c|c|c|c|c|}
\hline Formulação & Sericina $\%(\mathrm{~m} / \mathrm{V})$ & Alginato $\%(\mathrm{~m} / \mathrm{V})$ & Cetoprofeno $\%(\mathrm{~m} / \mathrm{V})$ & PEG \%(m/V) \\
\hline $\mathrm{C} 1$ & 2,5 & 1 & 2 & 0 \\
\hline $\mathrm{C} 2$ & 2,5 & 1,5 & 2 & 0 \\
\hline $\mathrm{C} 3$ & 2,5 & 2,8 & 2 & 0 \\
\hline $\mathrm{C} 4$ & 2,5 & 2,8 & 2 & 5 \\
\hline C5 & 0 & 2,8 & 2 & 0 \\
\hline
\end{tabular}

Utilizando-se de uma adaptação da metodologia utilizada por Khandai et al. (2010), as partículas foram preparadas por gelificação por gotejamento. Este método consistiu no gotejamento da solução com sericina, alginato e cetoprofeno em solução de cloreto de cálcio $(\mathrm{CaCl}) 3 \%$ sob agitação magnética, a fim de que houvesse rápida gelificação da solução. Após esta etapa, as partículas obtidas foram colocadas sob agitação em jar test a $100 \mathrm{rpm}$ por 30 minutos, com o intuito de completar a reticulação dos íons de cálcio difundidos. Por fím, foram lavadas com água deionizada, secas a temperatura ambiente e acondicionadas em frascos fechados e identificados.

\subsection{Ensaios de Incorporação}

Para realizar os ensaios de incorporação de cada formulação, foram pesados $0,1 \mathrm{~g}$ de cada formulação, adicionados a um balão volumétrico com $500 \mathrm{~mL}$ de tampão fosfato ( $\mathrm{pH}$ 6,8). As soluções foram mantidas em repouso por 24 horas (Vidart et al., 2015), e então, submetidas a sonicação, por 15 minutos, a fim de que todo o cetoprofeno presente fosse liberado. Após este período, a solução foi filtrada em filtro $0,45 \mu \mathrm{m}$ e teve sua absorbância determinada por espectroscopia UV-visível no comprimento de onda específico do cetoprofeno $(258 \mathrm{~nm})$. 
A eficiência de incorporação foi calculada a partir da Equação 1.

$$
\text { Eficiência de incorporação }=\frac{\text { Concentração de fármaco obtido }}{\text { Concentração de fármaco teórico }} \times 100
$$

\section{RESULTADOS E DISCUSSÕES}

A Figura 1 apresenta as diferentes partículas obtidas a partir do planejamento apresentado na Tabela 1.

Figura 1 - Imagens das partículas obtidas pelas 5 formulações C1, C2, C3, C4, C5.

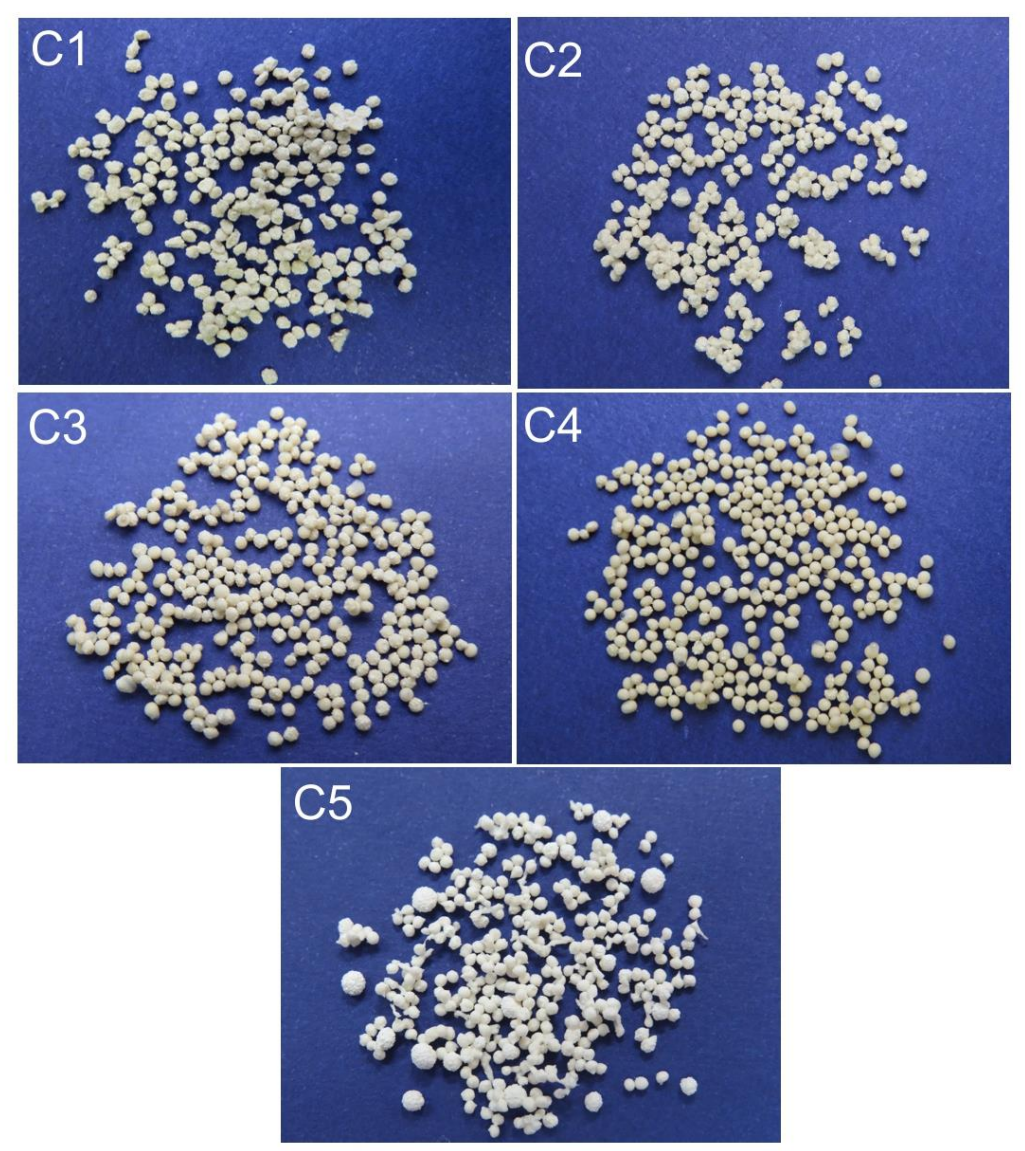

Pode-se observar que as partículas C5, cuja composição não apresenta sericina, é a que apresenta mais irregularidade e heterogeneidade nos tamanhos das partículas. Portanto, podese concluir que a sericina melhora as características das partículas obtidas. As partículas $\mathrm{C} 1 \mathrm{e}$ $\mathrm{C} 2$, com menores quantidades de alginato, se apresentam mais frágeis e com formas irregulares, podendo apresentar características não reprodutíveis. As partículas C3 e C4, com a máxima quantidade de alginato testada, apresentam formato esférico mais definido, sendo isso observado mais significativamente na partícula $\mathrm{C} 4$, em que houve adição do reticulante polietilenoglicol (PEG). 
Para melhor avaliar as partículas obtidas, através da Equação 1 foi possível verificar a eficiência de incorporação apresentada por cada uma das formulações. Os resultados podem ser observados no gráfico em barras exposto na Figura 2.

Figura 2 - Eficiência de incorporação do cetoprofeno nas partículas C1 a C5.

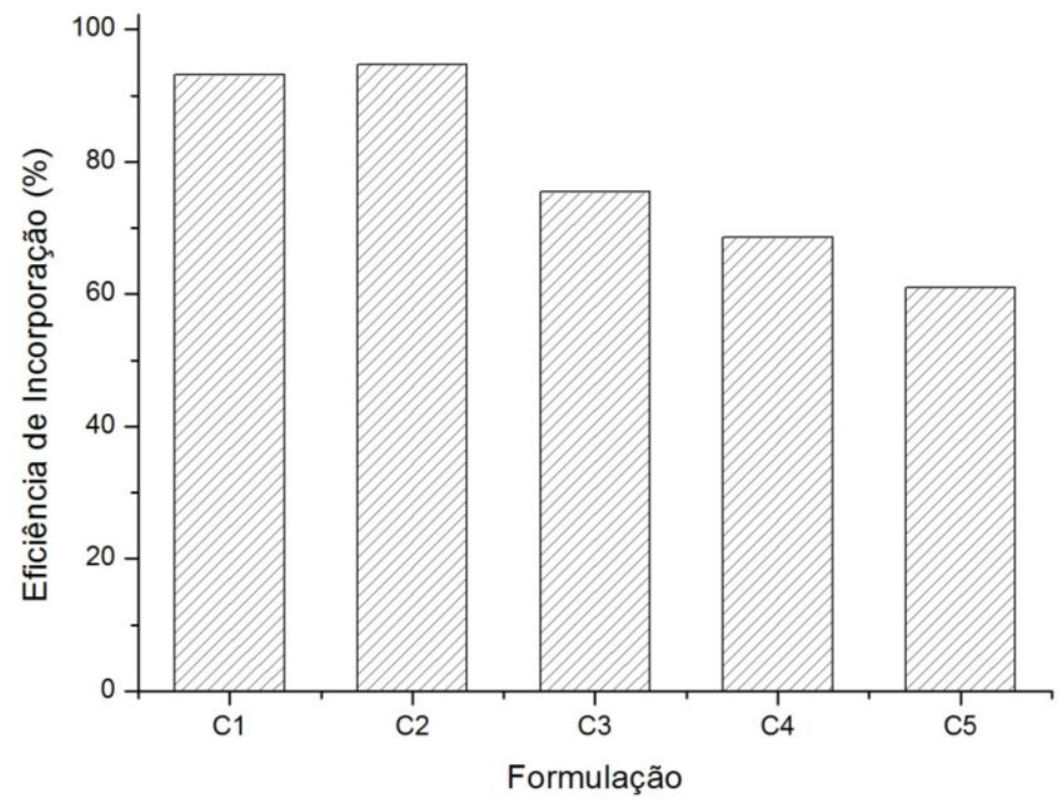

Pode-se observar da Figura 2, que a menor incorporação obtida foi para a partícula C5, que não tinha sericina. Portanto, o uso da sericina, além de melhorar as características da partícula, também melhorou a incorporação do cetoprofeno.

As partículas com menor quantidade de alginato $(\mathrm{C} 1$ e $\mathrm{C} 2)$ foram as que apresentaram as melhores eficiências de incorporação, com valores acima de $90 \%$. No entanto, foram as que se apresentaram mais frágeis, apresentando uma possibilidade de liberação mais rápida do fármaco. Ao comparar as partículas $\mathrm{C} 3$ e $\mathrm{C} 4$, tendo sido nessa última adicionado o PEG, pode-se observar que a eficiência de incorporação foi reduzida na partícula com PEG. Portanto, apesar de ele tornar as partículas mais regulares, a eficiência obtida não foi tão satisfatória.

\section{CONCLUSÕES}

Com os resultados apresentados acima é possível concluir que o método de extração de sericina por via física e autoclave, formação da blenda de alginato e sericina, incorporação do cetoprofeno e posterior formação das partículas apresentou alto grau de sucesso.

Quanto à incorporação de cetoprofeno à blenda de sericina e alginato, pode-se afirmar que a presença da sericina aumenta significativamente sua eficiência, além de gerar uma geometria mais bem definida das partículas. A presença do PEG como agente reticulante diminui a eficiência de incorporação, ainda que torne as partículas mais esféricas e homogêneas. Com relação ao alginato de sódio, é possível observar que partículas com baixa fração mássica não possuem geometria bem definida, apesar de apresentarem elevada eficiência de incorporação. Logo, verificou-se que as partículas ideais para a incorporação de 
cetoprofeno são as que apresentam frações mássicas de sericina e alginato equilibradas, como as formulações C2 e C3, sendo a partícula C3 a que apresenta o melhor resultado em termos de morfologia e de teor de incorporação do fármaco.

\section{AGRADECIMENTOS}

Os autores agradecem ao CNPq e FAPESP (Proc. 2015/13505-9) pelo apoio financeiro, e à empresa BRATAC pelo fornecimento dos casulos.

\section{REFERÊNCIAS}

ARAMWIT, P.; SIRITIENTONG, T.; SRICHANA, T. Potential applications of silk sericin, a natural protein from textile industry by-products. Waste Manag. Res, v. 30 (3), p. 217224, 2012.

CASTAGNETTI, C.; MARIELLA, J. Anti-inflammatory Drugs in Equine Neonatal Medicine. Part I: Nonsteroidal Anti-inflammatory Drugs. J. Equine Vet. Sci., v. 35, p. 475-480, 2015.

KHANDAI, M.; CHAKRABORTY, S.; SHARMA, A.; PATTNAIK, S.; PATRA, C. N.; DINDA, S. C.; SEN, K. K. Preparation and evaluation of algino-sericin mucoadhesive micro- spheres: An approach for sustained drug delivery. J. Adv. Pharm. Res., v. 1, p. 48-60, 2010.

MOREIRA, K, MIRANDA, L N, ZÉTOLA, M, PEZZINI, B R, BAZZO, G C Comprimidos contendo microesferas de cetoprofeno como sistema de liberação bifásica. Rev. Ciênc. Farm. Básica Apl., v. 33(1), p. 71-76, 2012.

SILVA, T. L.; GIMENES, M. L.; VIEIRA, M. G. A.; SILVA, M. G. C. Extração de sericina de casulos do bicho da seda (Bombyx mori) e formação de partículas a base de sericina e alginato. XXXVI Congresso Brasileiro de Sistemas Particulados. Maceió 2013.

SOARES, T.A.; VIDART, J. M. M.; DA SILVA, T. L.; GIMENES, M. L.; DA SILVA, M. G. C.; VIEIRA, M. G. A. Obtenção de micropartículas a base de sericina e alginato para incorporação de diclofenaco de sódio, em: Anais do XI Congresso Brasileiro de Engenharia Química em Iniciação Científica (COBEQ-IC), São Paulo:Blucher, 2015.

TOMADON JR., J. Obtenção da proteína sericina, com alta massa molecular, a partir de casulos Bombyx mori. Dissertação (Mestrado). Universidade Estadual de Maringá, Maringá, 2011.

VIDART, J. M. M.; SOARES, T. A.; SILVA, T. L.; GIMENES, M. L.; VIEIRA, M. G. A.;SILVA, M. G. C. Avaliação da eficiência de incorporação de diclofenaco de sódio em partićulas de sericina e alginato, em: Anais do XXXVII Congresso Brasileiro de Sistemas Particulados (ENEMP), São Paulo:Blucher, 2015 